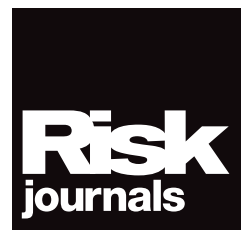

Journal of Financial Market Infrastructures 6(2/3), 1-32

DOI: $10.21314 / J F M I .2018 .088$

Research Paper

\title{
The impact of de-tiering in the United Kingdom's large-value payment system
}

\section{Evangelos Benos, Gerardo Ferrara and Pedro Gurrola-Perez}

Bank of England, 20 Moorgate, London EC2R 6DA, UK; emails: evangelos.benos@bankofengland.co.uk, gerardo.ferrara@bankofengland.co.uk, pedro.gurrola-perez@ bankofengland.co.uk

(Received July 2017; revised October 2017; accepted November 2017)

\begin{abstract}
Large-value payment systems (LVPSs) often have a tiered structure, whereby only a limited number of banks have direct access to these systems, while every other institution accesses it through agency arrangements with direct participants. As such, a high degree of tiering is often perceived as being associated with credit and operational risks. In this paper, we use data around five recent de-tiering events in the United Kingdom's LVPS (Clearing House Automated Payment System) to assess the impact of de-tiering on these risks as well as on liquidity usage. We find that the impact of de-tiering is largest on credit risk, where average intraday exposures between firstand second-tier banks drop by anywhere between $£ 0.3$ billion and $£ 1.5$ billion per bank, while the cost of insuring against the losses arising from these exposures drops by $£ 4$ million to $£ 19$ million per bank, per year. Nevertheless, the impact of these de-tiering events on operational risk and liquidity usage appears to be economically small.
\end{abstract}

Keywords: payment systems; tiering; credit risk; liquidity usage; operational risk. 


\section{INTRODUCTION}

Large-value payment systems (LVPSs) often have a tiered structure, whereby a limited number of (first-tier) banks have direct access to these systems and act as correspondents for every other (second-tier) institution wishing to make or receive a payment (see Figure 1). The degree of tiering in a payment system is of interest to policy makers and regulators because of its potential effect on credit risk (between first- and second-tier members), liquidity risk and operational risk. The Principles for Financial Market Infrastructures, for example, point out that the dependencies and risk exposures inherent in tiered arrangements in financial market infrastructures can present risks to their smooth functioning as well as to their participants and the financial markets more broadly (CPMI-IOSCO 2012).

There is substantial variation in the degree of tiering across the world's LVPSs. Table 1 shows activity summary statistics for some of these systems, along with their degree of tiering as captured by the ratio of the number of first-tier to total system participants. ${ }^{1}$ As one can see, the United Kingdom's Clearing House Automated Payment System (CHAPS) is the most tiered system, while Switzerland's SIC and Japan's BOJ-NET are the least tiered, with all participating banks having direct access to them. This variation in tiering across payment systems is partly due to historical reasons, but it may also reflect participation costs or other economic incentives along with regulatory mandates.

In the case of CHAPS, policy discussions have highlighted the merits of reducing the level of tiering. For example, in a recent assessment, the International Monetary Fund (IMF) stated that:

De-tiering helps address (for its part) the too-big-to-fail nature of banks and will bring the UK more in line with international practices in, for example, the EU and the United States, where most banks have direct access to the RTGS system.

The IMF was also of the view that "further de-tiering is needed" (Internation Monetary Fund 2016). Although there has been an increase in the number of CHAPS direct members (from fourteen in 2007 to twenty-six in 2017), the question remains as to what the impact of de-tiering has been so far and whether more de-tiering would be desirable.

Our paper is the first to use data around actual de-tiering events to quantify the economic effects of tiering in one of the world's largest real-time gross settlement (RTGS) payment systems. In particular, we examine the impact of five recent CHAPS

\footnotetext{
${ }^{1}$ Because of structural differences across different financial systems, this ratio only provides a relative measure of tiering. For a more accurate picture, other factors may need to be taken into account, such as the fact that some participants with direct access may still choose to operate through correspondent banks.
} 
FIGURE 1 A tiered structure.

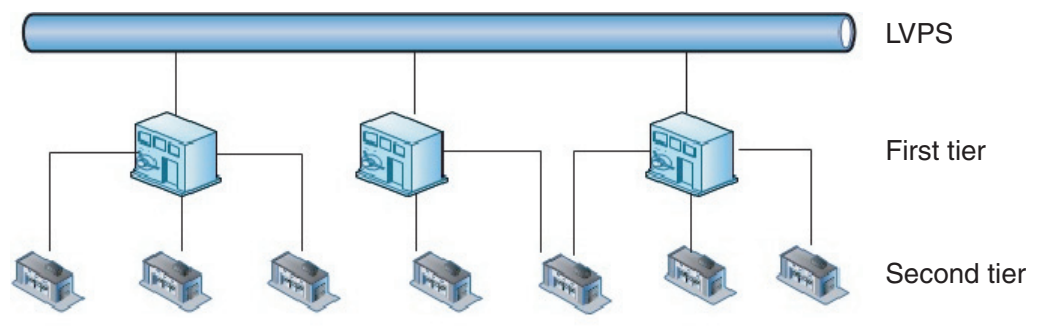

"First-tier" banks with direct access to the payment system act as correspondents for "second-tier" institutions.

de-tiering events on bank credit, liquidity and operational risks. ${ }^{2}$ Previous attempts to assess these risks have been based exclusively on simulations. However, simulation studies typically use models that do not capture banks' strategic behavior and therefore are less realistic. Instead, we look at actual bank behavior around these de-tiering events and, as such, we are able to capture equilibrium outcomes and more accurately characterize the impact of de-tiering. In addition, we provide monetary estimates of the expected costs associated with each of the above risks and of the way these costs change after the de-tiering events. For credit risk, we do this by estimating what a bank would be expected to have to pay in order to insure itself against the intraday exposures that arise as a result of tiering. For liquidity and operational risks, we estimate the opportunity costs of deployed liquidity and of payments that are delayed as a result of operational outages, respectively.

Our findings suggest that the de-tiering events mostly affect the magnitude and cost of intraday credit risk between first- and second-tier banks. More precisely, we find that de-tiering reduces average intraday exposures, between first- and second-tier banks, by anywhere between $£ 0.3$ billion and $£ 1.5$ billion for each affected bank. ${ }^{3}$ Maximum intraday exposures are reduced by up to $£ 2.7$ billion per bank. The associated reductions in the implied insurance premiums fluctuate between $£ 4$ million and $£ 19$ million per bank, per year, depending on whether the bank is joining the first tier or is a legacy first-tier one whose clients join the first tier.

In addition, de-tiering does not seem to cause liquidity costs to increase, as the amount of liquidity deployed by first-tier banks is statistically uncorrelated with the de-tiering events. In any case, the cost of liquidity appears to be economically small

\footnotetext{
${ }^{2}$ For simplicity, we refer to the cost of liquidity usage as "liquidity risk" throughout the paper.

${ }^{3}$ That is, either for a second-tier bank that joins the first tier or a first-tier bank whose clients join the first tier.
} 


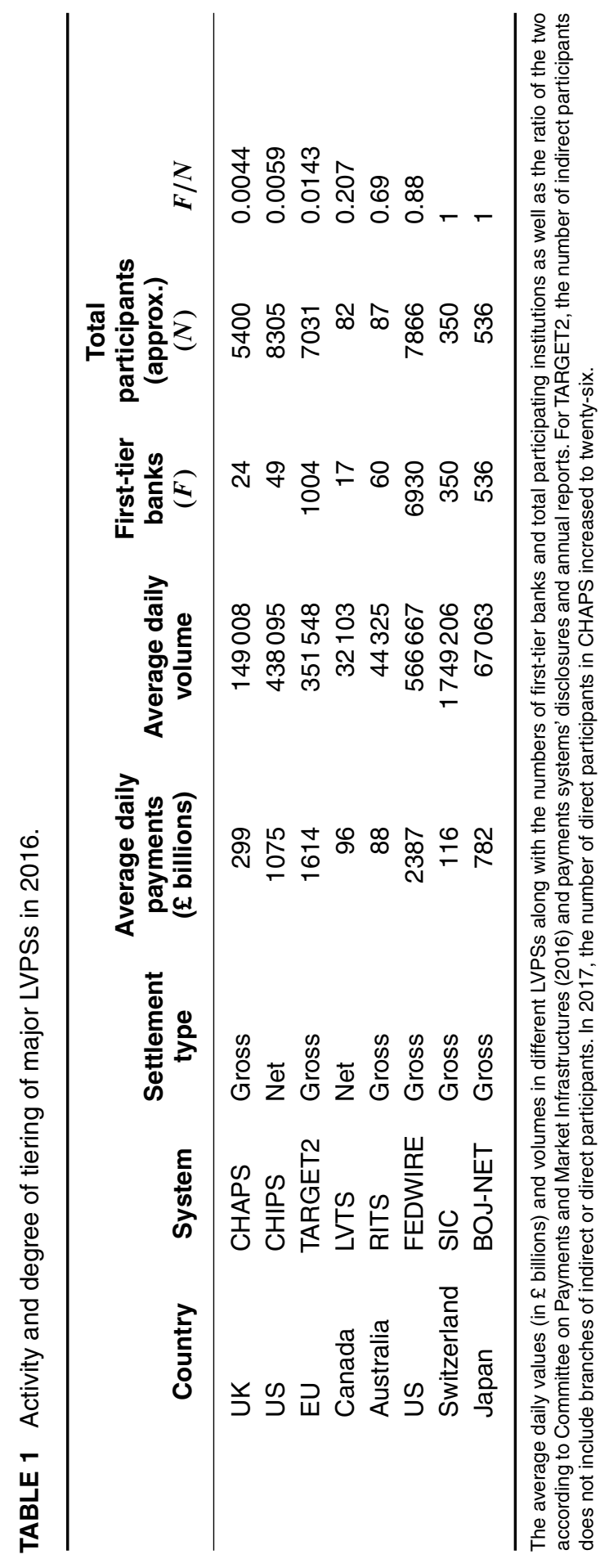


in CHAPS, so any further potential increases to liquidity usage due to de-tiering are unlikely to be economically significant. Similarly, we also find that the expected monetary cost resulting from individual bank operational outages is small, to the extent that de-tiering can only have, in expectation, minor incremental effects on operational risk. The other possible effects of de-tiering, such as on bank resolution, on competition or on legal risk, are beyond the scope of our analysis.

The rest of this paper is organized as follows. In Section 2, we review the relevant literature. In Section 3, we describe the institutional characteristics of CHAPS and the data used in our analysis. In Section 4, we describe the methodology for assessing the credit, liquidity and operational risks associated with de-tiering and present the results as applied to CHAPS. Section 5 concludes.

\section{LITERATURE REVIEW}

Our paper is related to previous studies that have sought to explain the economic rationale of tiering in LVPSs and analyze its effects on credit risk and liquidity usage.

A number of papers rationalize tiering using monitoring-efficiency arguments. For example, in characterizing an efficient payment system, Rochet and Tirole (1996) argue that such a system should enable bilateral intraday overdrafts similar to the ones that exist between correspondent and client banks in a tiered payment system. This enables the banks to take advantage of the soft information that they may have about their counterparties and helps overcome the inefficiency in credit provision caused by the uniformity of the central bank's overdraft rules. Related to that, Jackson and Manning (2007) show that a central bank can optimally require collateral for all of the intraday lending that it does, even if only a subset of participants are safe and have low collateral costs. This is because the riskier participants can benefit indirectly from central bank credit by corresponding via the safe banks in a tiered structure. Kahn and Roberds (2009) develop an explicit theory of tiering which shares elements of that intuition. They set up a static model in which banks seek to meet their payment obligations to each other but need to account for settlement risk (ie, the risk that bank A makes a payment to bank B but does not receive its dues because bank B has in the meantime defaulted). One solution is for banks to post collateral, which is expensive. Alternatively, banks may monitor each other, and tiering is one way to achieve this in a decentralized system, as less reliable banks settle through more reliable ones, who act as their monitors. Chapman et al (2013) build on this intuition in a dynamic setup. In their paper, first-tier banks observe the credit history of their second-tier clients, which allows them to better assess their creditworthiness. This, in turn, allows for a more efficient allocation of credit.

Given the implications of tiering on bank intraday liquidity, our paper is also related to studies that model bank intraday liquidity management in payment networks. The 
seminal paper here is by Bech and Garratt (2003), who show that in order to minimize liquidity costs, banks may strategically delay their outgoing payments, potentially giving rise to socially inefficient equilibriums. Abbink et al (2017) provide laboratory evidence of such equilibriums and show that inefficient equilibriums tend to be stable, ie, once banks start collectively delaying payments, it is difficult to get them to change their behavior.

Our paper is more closely related to a literature that has sought to empirically assess the impact of LVPS tiering on intraday credit risk and liquidity usage. Unsurprisingly, many of these studies use data from CHAPS, since CHAPS is one of the most tiered systems in the world. Bank of England (2004a) and Harrison et al (2005) are the first to assess the size of unsecured intraday credit exposures of first-tier CHAPS banks toward their second-tier clients. They both find that, under normal circumstances, these exposures are not large and, as a result, the credit risk that accrues to first-tier banks is not material. However, there are instances when these exposures may be larger, if short-lived. For example, Bank of England (2004a) reports that, according to the 2003 correspondent banking survey, the largest recorded intraday exposure to a single second-tier bank for that year was between $£ 3.5$ billion and $£ 4$ billion. Harrison et al (2005) calculate that under more extreme assumptions, substantial credit risk can arise. Lasaosa and Tudela (2008) employ the Bank of Finland payments simulator (BoFPS) to see how credit risk and liquidity savings are affected when up to seven of the smallest first-tier CHAPS banks join the second tier. They find that an increase in credit risk arises from intraday overdrafts, along with an increase in liquidity efficiency, but both of these effects are economically small. Similar results are obtained by Arculus et al (2012), who also use the BoFPS, this time calibrated to the Australian LVPS, a system characterized by very little tiering. Their simulations show limited liquidity benefits resulting from increased tiering. The authors attribute this to the usage of a liquidity-savings mechanism, which helps first-tier banks economize on liquidity. Adams et al (2010) seek to understand what role liquidity costs play in a bank's decision to directly or indirectly access an RTGS system. These authors assume that banks trade off a higher liquidity cost if they are on the first tier, while they pay a flat fee to their correspondent bank, which is determined by a Nash bargaining rule, if they are on the second tier. Calibrating this model to CHAPS data, the authors are able to generate realistic tiering patterns, suggesting that liquidity cost is a likely driver of tiering. Our paper adds significantly to this literature by analyzing the effect of actual de-tiering events as opposed to running simulations. As such, our paper provides cleaner evidence on the impact of tiering, since it makes no assumptions about bank behavior.

Another relevant stream of the literature is that on the impact of operational incidents in payment systems. Bech and Garratt (2012) show theoretically that such incidents can render the payment system illiquid by causing participants' behavior 
to change. In particular, in cases of wide-scale disruptions that affect multiple participants, banks may choose to withhold payments, which can result in a breakdown of payment coordination and a drying-up of liquidity. Bedford et al (2004) use simulation techniques to study the impact of such outages in CHAPS. They conclude that the system exhibits a high level of resilience, reflecting the effectiveness of the operational risk controls that are in place and the ample amount of liquidity available in the system. Merrouche and Schanz (2009) investigate instances of isolated operational outages, where a stricken bank is able to receive but unable to send payments. In those instances, the bank may act as a liquidity sink if other banks continue making payments to it. Using data from CHAPS, the authors find that during outages, healthy banks on average reduce their payment outflows to the stricken bank by $40 \%$. This substantially reduces the risk of spillover from the outage, as less liquidity becomes trapped. Benos et al (2012) estimate the expected amount and replacement cost of forgone liquidity during such incidents in CHAPS. They find that the expected cost of liquidity shortages is economically small (about $£ 6000$ to $£ 7000$ per bank, per day). This is consistent with the evidence from other RTGS systems: Berge and Christophersen (2012) show that while a disruption among the four largest banks of the Norwegian settlement system (NBO) could affect the ability of other banks to make payments, this effect is significantly reduced if banks quickly stop making payments to the stricken bank so that it does not become a liquidity sink. Clarke and Hancock (2013) show that the liquidity-saving features of the Australian RTGS, such as the bilateral-offset algorithm, minimize the impact of outages by reducing the overall reliance of the system on available liquidity.

Finally, our paper is related to a number of more recent empirical studies of bank behavior and liquidity usage in CHAPS. While these studies do not explicitly examine tiering, their findings on CHAPS liquidity usage are largely influenced by the high degree of CHAPS tiering. Benos et al (2014) find that concerns about counterparty risk, in the wake of Lehman's default, caused some CHAPS banks to delay outgoing payments to other CHAPS banks that were perceived as being at risk. As a result, payment coordination and recycling dropped, and CHAPS banks were forced to deploy more liquidity to meet their payment obligations. Denbee et al (2015) show that smaller CHAPS banks tend to provide more liquidity than larger ones relative to their payment flows. This effect became more pronounced after Lehman's default. Benos and Harper (2016) show that the degree of payment recycling in CHAPS has not been affected by the larger amount of available liquidity in the form of reserves that has resulted from the Bank of England's quantitative easing (QE) program. Among other things, Benos and Harper (2016) attribute this to the high degree of tiering in CHAPS, which makes it relatively easier for banks to coordinate their payments. 


\section{INSTITUTIONAL DETAILS, DATA AND NOTATION}

CHAPS is the United Kingdom's same-day high-value payment system. CHAPS uses an RTGS system, whereby each individual payment is settled in real time across its first-tier banks' settlement accounts at the Bank of England. It is the only UK payment system that guarantees real-time finality on any value, in central bank money. CHAPS is one of the largest RTGS systems in the world, offering risk-free and irrevocable same-day payments to meet the sterling RTGS payment requirements of its twentysix direct participants. CHAPS is also a critical mechanism for ensuring liquidity in the financial markets, as it is used by banks for sterling interbank loans. Most of the daily value processed by CHAPS is from wholesale transactions, where CHAPS acts as the portal through which international sterling flows take place. CHAPS is used by banks, building societies and other payment service providers to pay each other. This includes payments for house purchases, although this represents only around $1 \%$ of the daily value processed. ${ }^{4}$

As mentioned earlier, CHAPS is a highly tiered system. This is partly due to historical reasons and, in particular, regulatory restrictions on joint-stock banking, which were in place in the nineteenth century. These gave the Bank of England a monopoly on joint-stock banking, prevented other banks from expanding, and meant that country banks needed to have a London correspondent account in order to settle payments in London and other regions (Norman et al 2011). Another reason for the high degree of tiering in CHAPS has to do with the status of London as a financial center, where international banks feel comfortable with corresponding banking. In addition, the technical and liquidity costs associated with direct participation may have discouraged banks from becoming direct members (Finan et al 2013). ${ }^{5}$

\footnotetext{
${ }^{4}$ See http://bit.ly/2CzXE6i. For a more detailed description of CHAPS attributes, as well as those of other RTGS systems, see Manning et al (2009). It should be highlighted that responsibility for the CHAPS system transferred to the Bank of England in November 2017.

${ }^{5}$ In recent years, CHAPS has reduced the costs of direct participation. There is no joining fee, and the annual shareholder charge is split equally among participants (it is currently $£ 18589$ per participant). In addition, a direct participant has to pay a participation charge, which is based on prior-year volumes as well as the costs of holding a Bank of England settlement account (an ongoing $£ 15000$ management fee plus debit item charges), and the SWIFT tariff fees (see http://bit.ly/2qroKrF). On aggregate, these costs seem relatively moderate, even for a low-volume institution. However, operational participation may be costly: a direct participant needs to comply with the technical and operational requirements of the system, which predominantly relate to connectivity and compatibility (eg, a connection to the SWIFT payment messaging network, SWIFT interfaces), resilience, financial stability and security. The cost implications of technical and operational requirements, together with the credit and liquidity risk management requirements of direct participation, can be particularly onerous for smaller players (Financial Conduct Authority and Payments Systems Regulator 2014).
} 
TABLE 2 De-tiering events in CHAPS.

\begin{tabular}{ll}
\hline De-tiered banks & De-tiering date \\
\hline BNP & July 13, 2015 \\
Bank of New York & May 19, 2014 \\
Handelsbanken & November 11, 2013 \\
State Street & September 17, 2012 \\
Bank of America & October 18, 2010 \\
\hline
\end{tabular}

All instances of second-tier banks who joined the first tier between September 20, 2010 and February 12, 2016.

Tiering in CHAPS has often been thought to introduce unnecessary credit and operational risks. As a result, the Bank of England has encouraged the expansion of CHAPS membership (Bank of England 2004b; Salmon 2011). In line with this, the number of direct members (in sterling payments) increased from twelve in 2004 to eighteen in 2011. More broadly, the international standards set out by the Committee on Payment and Settlement Systems-Technical Committee of the International Organization of Securities Commissions in the Principles for Financial Market Infrastructures (CPMI-IOSCO 2012) also highlighted the risks that the dependencies and exposures inherent in tiered arrangements can create and provided guidance on how market infrastructures could address them. As a result, in recent years, additional initiatives have been taken to further reduce the degree of tiering in CHAPS. In 2012, for example, CHAPS introduced tiering criteria, by which indirect participants processing payments above a certain threshold may be required to become direct members, and correspondent banks were made responsible for monitoring the extent to which their second-tier clients have exceeded these thresholds (see http://bit.ly/2CBphvO for more details).

Our study focuses on five recent de-tiering events, whereby five second-tier banks joined the first tier and, as a result, the number of first-tier CHAPS members increased from seventeen to twenty-two (Table 2) ${ }^{6}$ Our sample period is from September 20, 2010 (a month before the first event) to February 12, 2016, with a total of 1365 days.

To study the impact of these de-tiering events, we use data on all payments sent through CHAPS on a daily basis, over the above-mentioned time period. ${ }^{7}$ The data includes information on the identities of the first-tier senders and receivers, the iden-

\footnotetext{
${ }^{6}$ Information about the banks that have joined CHAPS in recent years can be found at www.chapsco .co.uk/media/press-releases.

${ }^{7}$ During this period, CHAPS was open during a ten-hour and twenty-minute window each business day, opening for payments at 06:00. Participants are not obliged to be open for business at 06:00, but they must be open by 08:00 and sending payments by 10:00. Since June 20, 2016, the Bank of England RTGS, which processes CHAPS payments, has been open for an extra hour and forty minutes, closing at 18:00 instead of 16:20.
} 
tities of their client banks (for payments made or received on behalf of second-tier banks) and the value and timing of payments aggregated at one-minute intervals. The graphic below summarizes the structure of the data:

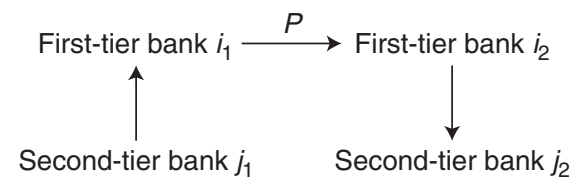

In our analysis, we treat branches and legal entities that belong to the same parent company as a single entity. Finally, although we observe payments by first-tier banks on behalf of second-tier ones, we do not observe the time of the payment message received by the first-tier banks. As such, we do not know if or for how long firsttier banks delay the execution of their customers' orders. Throughout, we denote by $P_{s t}^{\mathrm{OUT} / \mathrm{IN}}(i, j)$ the cumulative amount paid/received by the first-tier bank $i$ on behalf of second-tier bank $j$, on day $s$ and up to time $t$ :

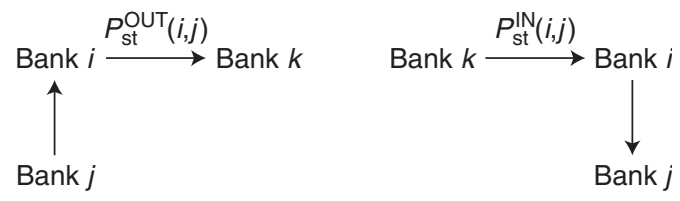

Figure 2 shows the aggregate values and volumes of daily payments made in CHAPS as well as the values and volumes of payments made on behalf of second-tier banks. Aggregate payment values are in the range $£ 139$ billion- $£ 426$ billion between 2011 and 2016, while payment volumes fluctuate between 60000 and 90000 messages daily. Payments on behalf of second-tier banks are almost half of total payments, which is indicative of the high degree of tiering in CHAPS. It is noteworthy that payments on behalf of second-tier banks do not appear to change after each of the de-tiering events. This is mainly because, to a large extent, the new first-tier banks continue to make payments via their correspondent banks.

\section{ANALYSIS AND RESULTS}

In this section, we define and calculate the metrics of credit, liquidity and operational risks associated with tiering and study the impact that the five de-tiering events had on the magnitude of these risks. In theory, the degree of tiering should be related to the credit, liquidity and operational risks borne by first- and second-tier banks as follows.

(1) A less tiered structure should decrease credit risk. This is because when a first-tier CHAPS bank makes (receives) a payment on behalf of a second-tier client, it does so without immediately receiving (sending) any funds from (to) its second-tier client. Instead, all dues are netted at the end of the day. This 
FIGURE 2 CHAPS daily payment values and volumes.
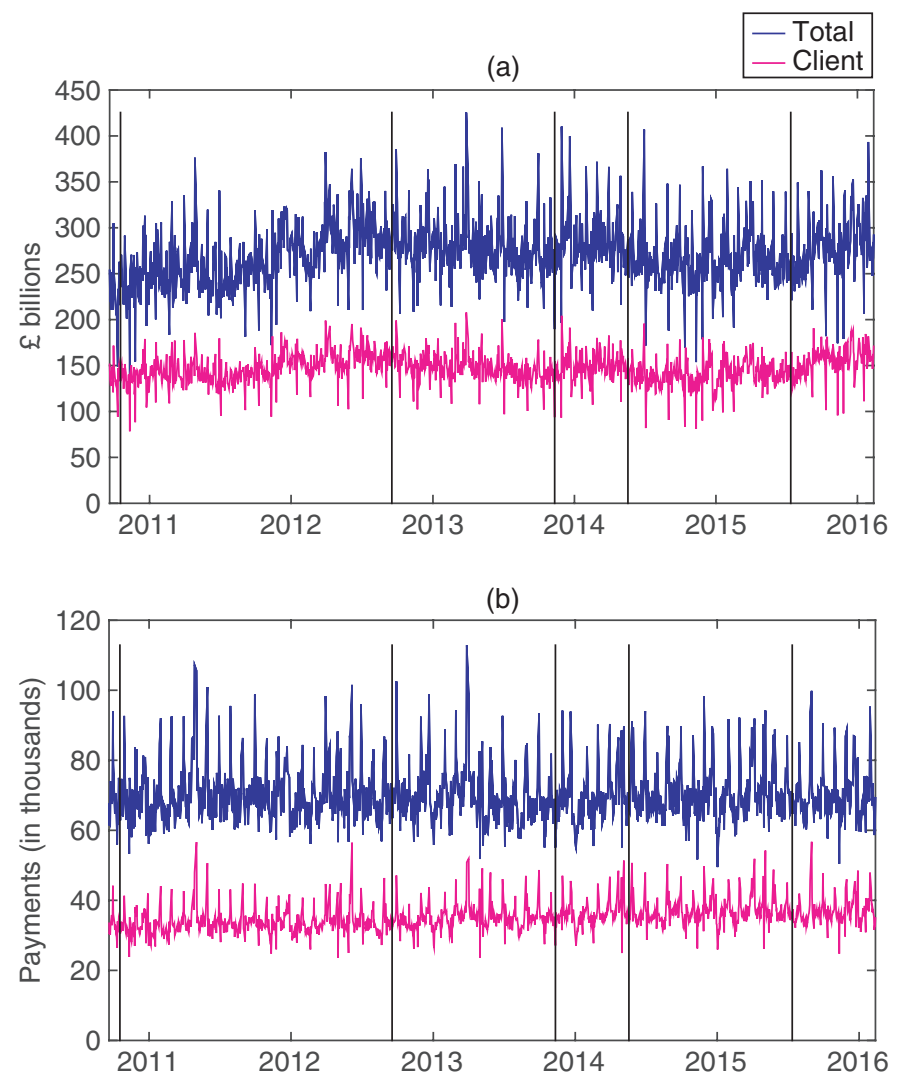

(a) Daily payment values (in £ billions). (b) Daily payment volumes (in thousands of payments). The blue (upper) lines show total values and volumes, while the pink (lower) lines show values and volumes of payments made on behalf of second-tier client banks. The sample period is September 2010 to February 2016. The vertical lines indicate de-tiering events.

effectively creates an intraday exposure between the banks of the two tiers, which means that should one bank default during the day, the other is liable to potential losses arising from this exposure. This is akin to the credit risk that arises in deferred net settlement payment systems as formalized in Kahn and Roberds (1998). Thus, we should observe a reduction in credit risk after each of the de-tiering events in our sample.

(2) A less tiered structure should increase liquidity cost. First, this is because of payment pooling. In a tiered structure, any funds received by a first-tier bank on behalf of its clients can be used intraday to fund outgoing payments of the 
first-tier bank that are made on behalf of either itself or another client bank. This means that the first-tier bank will have to deploy less of its own liquidity (in the form of reserves and collateral posted with the Bank of England) to meet its payment obligations. Thus, forcing payments to flow only between fewer (first-tier) banks effectively creates a liquidity pool that can be utilized by first-tier banks to make other CHAPS payments. Second, it is possible for first-tier banks to internalize payments that are made between two of its clients. This means that a payment between client A and client B of the same CHAPS first-tier bank can be settled outside of CHAPS by making a book entry in the balance sheet of the first-tier correspondent bank and without needing to deploy liquidity. Finally, any payments due between a correspondent bank and its clients are netted, which means that the amount of liquidity used is less than what would have been used if the client banks had been direct participants. These effects have previously been identified in simulation studies (see, for example, Adams et al 2010) and suggest that the amount and cost of liquidity used should rise after each of the de-tiering events.

(3) A less tiered structure should decrease operational risk resulting from individual bank outages. This is primarily because tiering creates operational dependencies. When a first-tier bank experiences an outage and, as a result, cannot make (or receive) payments, neither can its second-tier clients. In other words, individual bank outages at the first tier affect second-tier banks' ability to make or receive payments. ${ }^{8}$ However, a more tiered payment system should cope better against a system-wide outage, whereby no first-tier bank can send or receive payments. This is because, in a more tiered structure, a larger number of payments are internalized and are therefore not reliant on LVPS access.

In what follows, we empirically test these hypotheses and attempt to quantify the associated risks.

\subsection{Credit risk}

Credit risk between first- and second-tier banks arises when banks extend intraday credit to each other. The risk materializes if/when a bank fails to pay the (netted)

\footnotetext{
${ }^{8}$ As shown by Bech and Garratt (2012), banks may react strategically to a widespread operational outage by withholding their liquidity until the outage is resolved. In this paper, we do not examine the liquidity implications of operational incidents, given that Benos et al (2012) estimate this cost to be small in CHAPS and that we do a separate analysis of overall liquidity usage around the de-tiering events.
} 
amounts due at the end of the business day. Credit risk arises for both first- and second-tier institutions. ${ }^{9}$

- First-tier banks usually offer intraday overdraft facilities to their client banks when making outward payments on their behalf. This creates credit risk for first-tier banks, since, in case of a client bank default, the first-tier bank loses any intraday credit provided.

- Conversely, a second-tier bank is exposed to its settlement bank when it holds positive intraday balances with it. This happens when the first-tier bank receives more payments than it sends on behalf of its second-tier client. In this case, a default by the first-tier bank could result in the loss of any positive balances in the client's account.

For any first-tier bank that has one or more clients joining the first tier, we expect its credit risk to decrease, all else being equal, simply because de-tiering reduces the number of its second-tier clients. Similarly, the intraday credit exposures of a secondtier bank to its settlement bank(s) should be reduced once the second-tier bank joins the first tier. These exposures will not necessarily become zero, as the joining bank may still choose to obtain intraday credit from its former first-tier correspondent(s). ${ }^{10}$ To quantify the credit risk that arises between first- and second-tier banks, we make the following assumptions.

(a) Any payments due between first- and second-tier banks are paid off at the end of the business day. To our knowledge, this is precisely how dues between firstand second-tier CHAPS banks are settled.

(b) Intraday credit between first- and second-tier banks is mostly unsecured. Anecdotal evidence suggests that this is indeed the case between first- and second-tier banks. To the extent that intraday credit is collateralized, the intraday exposures that we calculate are an overestimate of the loss given default (LGD).

(c) For each bank, there cannot be multiple simultaneous counterparty defaults. We make this assumption because, in practice, the likelihood of multiple same-day defaults is extremely low.

Apart from examining how intraday exposures change as a result of de-tiering, we quantify credit risk by calculating what it would cost a bank to insure itself against any losses arising from these exposures. In doing so, we assume that the price of

\footnotetext{
${ }^{9}$ Of course, intraday credit risk may also arise between first-tier banks. For example, Jurgilas and Zikes (2014) document a positive price for unsecured intraday credit among CHAPS banks.

${ }^{10}$ The joining bank will also still be exposed to their clients, which were previously on the third tier and are now on the second tier. These exposures will not change as a result of a de-tiering event.
} 
insurance is actuarially fair in the sense that it equals the expected cost to the insurer. Under this (mild) assumption, the insurance premium is equal to the expected value of the loss, and a risk-averse bank will want to fully insure any potential losses (see Mas-Colell et al 1995, pp. 187-188).

Therefore, the expected cost of credit risk will equal the cost of insuring against any losses that arise as a result of intraday exposures if/when a counterparty fails. In particular, for each bank $i$, the sterling expected cost of its credit risk on day $s$ will be

$$
\mathbb{E}[\text { Credit Risk Cost }]_{i s}=\mathrm{LGD}_{i s} \times \mathrm{IP}_{s},
$$

where LGD is the loss given default and IP is the insurance premium. On aggregate, the expected credit risk cost on day $s$ will then be

$$
\mathbb{E}[\text { Credit Risk Cost }]_{s}=\sum_{i} \mathbb{E}[\text { Credit Risk Cost }]_{i s},
$$

where the sum is across all (or a subset of) the banks in the system. The daily LGD is a function of the intraday exposures between banks. We next estimate these exposures, both for first- and second-tier banks. ${ }^{11}$

\subsubsection{Intraday exposures between first- and second-tier banks}

One way to estimate the LGD of a first-tier bank $i$ in the case of a second-tier bank $j$ default on day $s$ is via the (time-weighted) average intraday credit exposure of bank $i$ to its client $j$ on that day. This is the time average net debit position of bank $i$ versus bank $j$ :

$$
\operatorname{Avg\_ Exposure}_{i j s}=\frac{1}{N} \sum_{t \in T} \max \left\{P_{s t}^{\mathrm{OuT}}(i, j)-P_{s t}^{\mathrm{IN}}(i, j), 0\right\},
$$

where $P_{s t}^{\mathrm{OUT} / \mathrm{IN}}(i, j)$ is the cumulative amount paid/received by first-tier bank $i$ on behalf of bank $j$ on day $s$ and up until time $t ; T=\left\{t_{1}, \ldots, t_{N}\right\}$ is a time partition of the business day; and $N$ is the number of time intervals in the partition. ${ }^{12}$ An upper bound for the LGD is the maximum credit exposure of bank $i$ to bank $j$ on day $s$ :

$$
\text { Max_Exposure }_{i j s}=\max _{t \in T}\left\{\max \left\{P_{s t}^{\mathrm{OUT}}(i, j)-P_{s t}^{\mathrm{IN}}(i, j), 0\right\}\right\} .
$$

These maximum exposures are typically short-lived; so while they are indicative of the potential intraday credit risks that might arise, they are economically less relevant than the average intraday exposures.

\footnotetext{
${ }^{11}$ For computational convenience, we do this using only payments that are larger than $£ 10$ million. After applying this threshold, we are still able to capture around $90 \%$ of the total daily value of payments made.

${ }^{12}$ In our case, there are $N=9$ hourly intervals.
} 
Given our assumption of at most one counterparty defaulting on any given day, we calculate for each bank $i$ the maximum, across all of its second-tier clients, of the above two metrics:

$$
\begin{aligned}
\text { Avg_Exposure }_{i s} & =\max _{j}\left\{\text { Avg_Exposure }_{i j s}\right\}, \\
\text { Max_Exposure }_{i s} & =\max _{j}\left\{\text { Max_Exposure }_{i j s}\right\} .
\end{aligned}
$$

In using maximums to calculate daily exposures, we conservatively assume that the defaulting second-tier bank is the one to which the first-tier correspondent has the largest intraday exposure.

We then calculate in a similar manner the credit risk that accrues to second-tier banks. Letting $P_{s t}^{\mathrm{IN} / \mathrm{OUT}}(i, j)$ be defined as before, the average and maximum credit exposures of second-tier bank $j$ to its settlement bank $i$ on day $s$ are

$$
\begin{aligned}
& \operatorname{Avg\_ Exposure}_{i j s}^{*}=\frac{1}{N} \sum_{t \in T} \max \left\{P_{s t}^{\mathrm{IN}}(i, j)-P_{s t}^{\mathrm{OUT}}(i, j), 0\right\}, \\
& \text { Max_Exposure }_{i j s}^{*}=\max _{t \in T} \max \left\{P_{s t}^{\mathrm{IN}}(i, j)-P_{s t}^{\mathrm{OUT}}(i, j), 0\right\},
\end{aligned}
$$

where $T=\left\{t_{1}, t_{2}, \ldots, t_{N}\right\}$ is again a partition of the business day.

Given that some second-tier banks have multiple first-tier correspondents, we take, as before, the maximum bilateral exposure across all first-tier institutions associated with second-tier bank $j$ :

$$
\begin{aligned}
& \text { Avg_Exposure }_{i s}^{*}=\max _{j}\left\{\text { Avg_Exposure }_{i j s}^{*}\right\},
\end{aligned}
$$

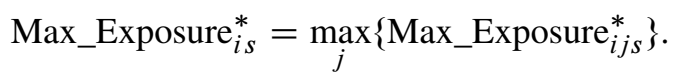

To estimate the magnitude of intraday exposure changes following each of the detiering events, we estimate the following panel specification separately for affected first- and second-tier banks:

$$
\text { Exposure }_{i s}=a+b \text { Event }_{i s}+c \text { SONIA }_{s}+u_{i}+e_{i s},
$$

where $i$ denotes banks, $s$ denotes days, "Exposure" is any of the variables defined in (4.5) and (4.7), "Event" is a bank-specific de-tiering event dummy, and SONIA (sterling overnight index average) is the effective reference overnight rate for unsecured transactions in the sterling market. In this setup, the coefficient of interest is $b$. Negative values of $b$ would suggest a decline in intraday exposures arising between first- and second-tier banks.

In Table 3, we report the results of this estimation. In columns (1)-(4), we report results for first-tier banks that had one of their second-tier clients joining the first tier. 
The estimated coefficients of the de-tiering event dummy are generally negative, and their significance tends to increase with the inclusion of controls. Also, they tend to be larger for Max_Exposure, which is consistent with expectations, since it is typically the largest clients that join the first tier. In terms of magnitudes, they suggest that daily intraday exposures drop on a daily basis by $£ 0.3$ billion- $£ 1.1$ billion, on average, for each of the affected first-tier banks, and depending on whether one measures average or maximum intraday exposures. In columns (5)-(8), we report results for the secondtier banks that join the first tier. The coefficients of the de-tiering event dummy are again negative but only borderline significant. Further, they are larger in magnitude than those of first-tier banks. The estimated coefficients suggest that second-tier bank intraday exposures drop by $£ 1.46$ billion- $£ 2.7$ billion daily on average for each bank, although this cannot be strongly statistically associated with the de-tiering events.

\subsubsection{Estimating the cost of credit risk}

We next estimate the expected cost of credit risk, as per (4.2), that arises as a result of the intraday exposures between first- and second-tier banks. We use the average daily CDS spread of the CHAPS banks as a proxy of the premium (IP) required to insure any losses associated with a bank's default. For this, we use the price of the five-year contract, as this is the most liquid term. In averaging the CDS spreads, we also assume that the insurance premium is the same across institutions. We note that CDS spreads involve an implicit assumption about the recovery rate, and that this assumption may yield different spreads than, for example, those obtained directly from credit rating implied probabilities. Another caveat to the use of CDS spreads is that they reflect the market's risk appetite, rather than the risk appetite of the regulator. While we are aware of these limitations, we believe they are unlikely to change the order of magnitude of the effect that we wish to quantify. Thus, we estimate the insurance premium as

$$
\mathrm{IP}_{s}=\frac{1}{I} \sum_{i \in I} \mathrm{CDS}_{i s}
$$

where $I$ is the number of CHAPS banks for which there is a traded CDS contract, and $\operatorname{CDS}_{i s}$ is the daily annualized spread of the five-year contract of bank $i$.

To calculate the change in the cost of intraday credit risk, we multiply each of the estimated "Event" dummy coefficients from Table 3 with the time average, minimum and maximum daily values of the insurance premium. These cost changes, expressed in $£$ thousands per bank, per day, are shown in Table 4. As one can see, the reduction in the expected costs of the intraday exposures between first- and second-tier banks, as a result of reduced tiering, averages between $£ 11000$ and $£ 135000$ per bank, per day (first row). This cost reduction is higher for second-tier banks, since these also experience the largest reductions in intraday exposures after they join the first tier. In 


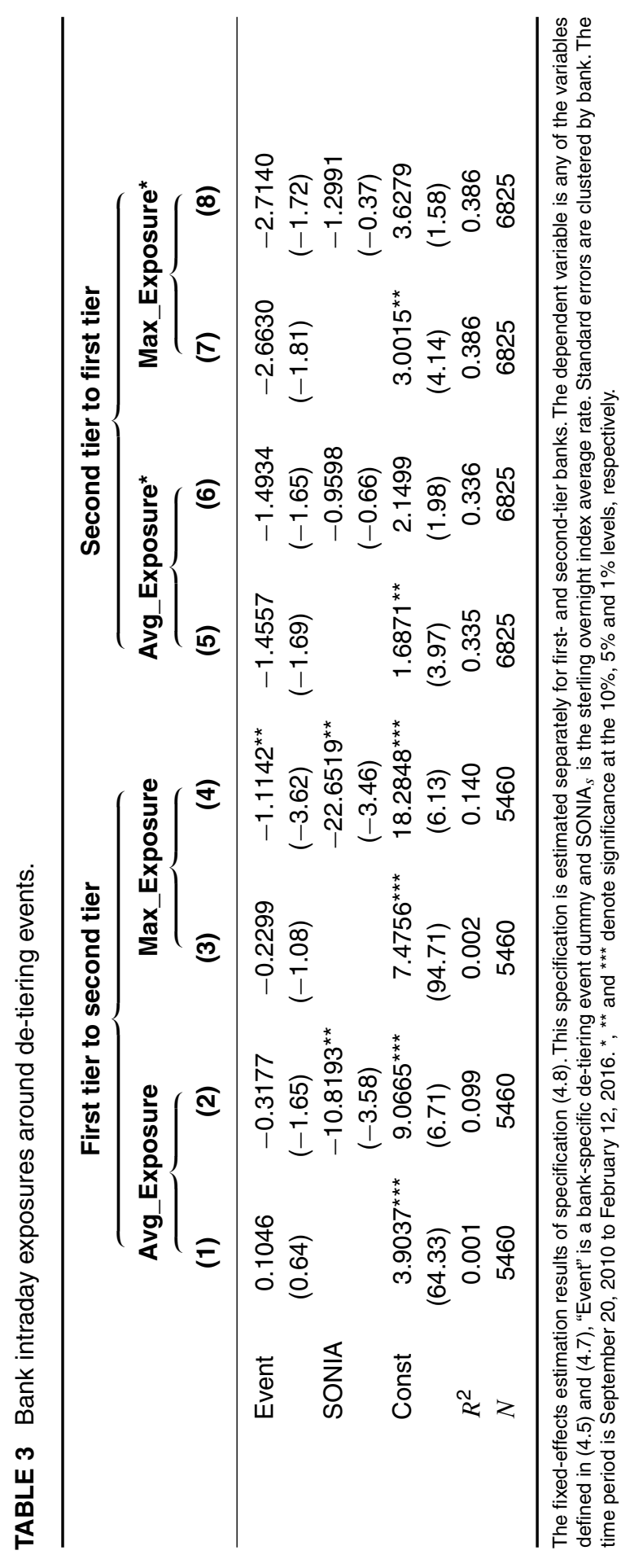


annual terms, the reduction in costs as shown in the first row, for example, amounts to anywhere between $£ 2.9$ million and $£ 33.7$ million for each bank. The numbers corresponding to the minimum/maximum CDS spreads observed during our sample period $(0.53 \%$ and $2.94 \%$, respectively) constitute a lower/upper bound for these cost reductions, since we effectively assume that every day in our sample period the insurance premium attains its minimum/maximum value. Again, depending on the way the intraday exposures are calculated, the associated daily cost reductions are at least as high as between $£ 6700$ and $£ 57500$ and at most as high as between $£ 27000$ and $£ 319000$ per bank on a daily basis. ${ }^{13}$

We finally look at system-wide intraday exposures (and their associated costs) arising across all CHAPS banks, so as to get a better sense of the overall magnitude of these costs. For this, we add up all the individual bank average and maximum intraday exposures as defined in (4.5) and (4.7):

$$
\begin{aligned}
\text { Avg_Exposure }_{s} & =\sum_{i \in \mathrm{FT}} \text { Avg_Exposure }_{i s}+\sum_{j \in \mathrm{ST}} \text { Avg_Exposure }_{j s}, \\
\text { Max_Exposure }_{s} & =\sum_{i \in \mathrm{FT}} \text { Max_Exposure }_{i s}+\sum_{j \in \mathrm{ST}} \text { Max_Exposure }_{j s},
\end{aligned}
$$

where FT and ST denote the sets of all first- and second-tier banks. ${ }^{14}$ We also calculate the daily expected costs of the system-wide intraday exposures at the prevailing insurance premiums by multiplying the system-wide exposures with the cross-bank average CDS spread:

$$
\mathbb{E}[\text { Credit Risk Cost }]_{s}=\text { Exposure }_{s} \times \mathrm{IP}_{s},
$$

where "Exposure" is either "Avg_Exposure" or "Max_Exposure". Figure 3 plots the daily aggregate intraday exposures that arise between all first- and second-tier banks, along with the average daily annualized, five-year CDS spread and the product of the two, which, as per (4.11), is our estimate of the daily cost of insuring against a potential loss. ${ }^{15}$ As is evident from Figure 3(c), the aggregate cost of insurance fluctuates between $£ 1$ million and $£ 6$ million daily for all banks in aggregate (or $£ 250$ million- $£ 1.5$ billion annually). The effect of the de-tiering events is less visible here, both because this calculation also includes (first- and second-tier) banks that were not affected by the events and because overall costs are largely driven by the prevailing CDS spreads.

\footnotetext{
${ }^{13}$ Annually, this cost reduction is between $£ 1.2$ million and $£ 14.4$ million at minimum and $£ 6.8$ million and £79.8 million at maximum for each bank.

${ }^{14}$ The sets are adjusted after each de-tiering event to include the new first-tier banks and exclude them from the second tier.

${ }^{15}$ In other words, it is the amount that all banks collectively would have to pay every day to insure themselves against losses arising from their intraday exposures.
} 


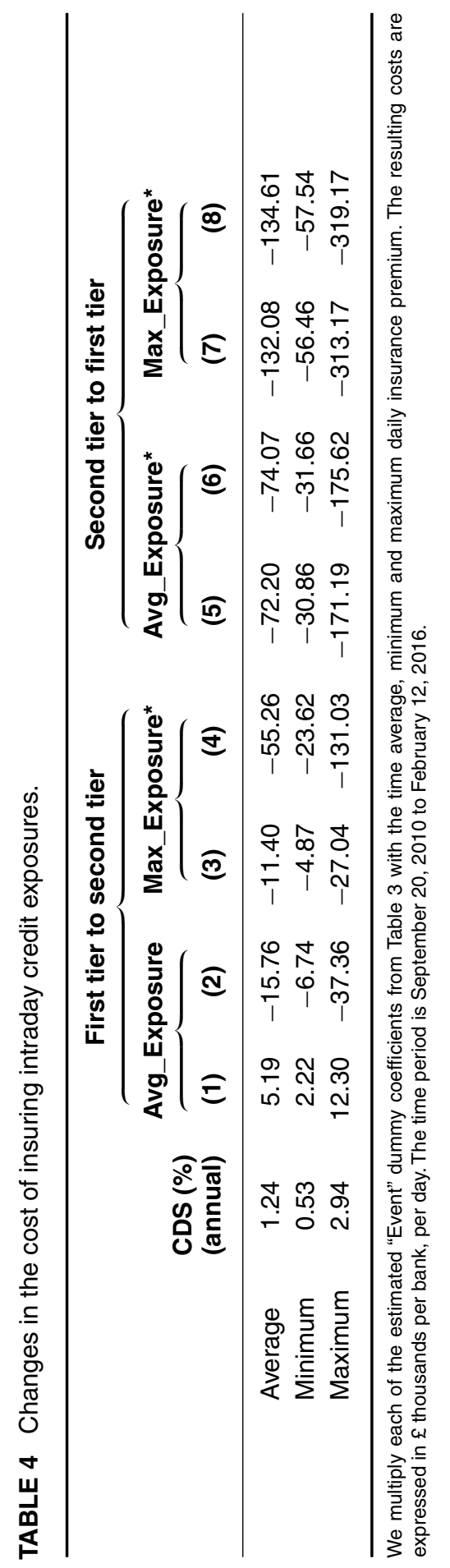


FIGURE 3 Daily aggregate intraday exposures, daily average CDS spread (\%, annualized) and daily expected cost of credit risk.
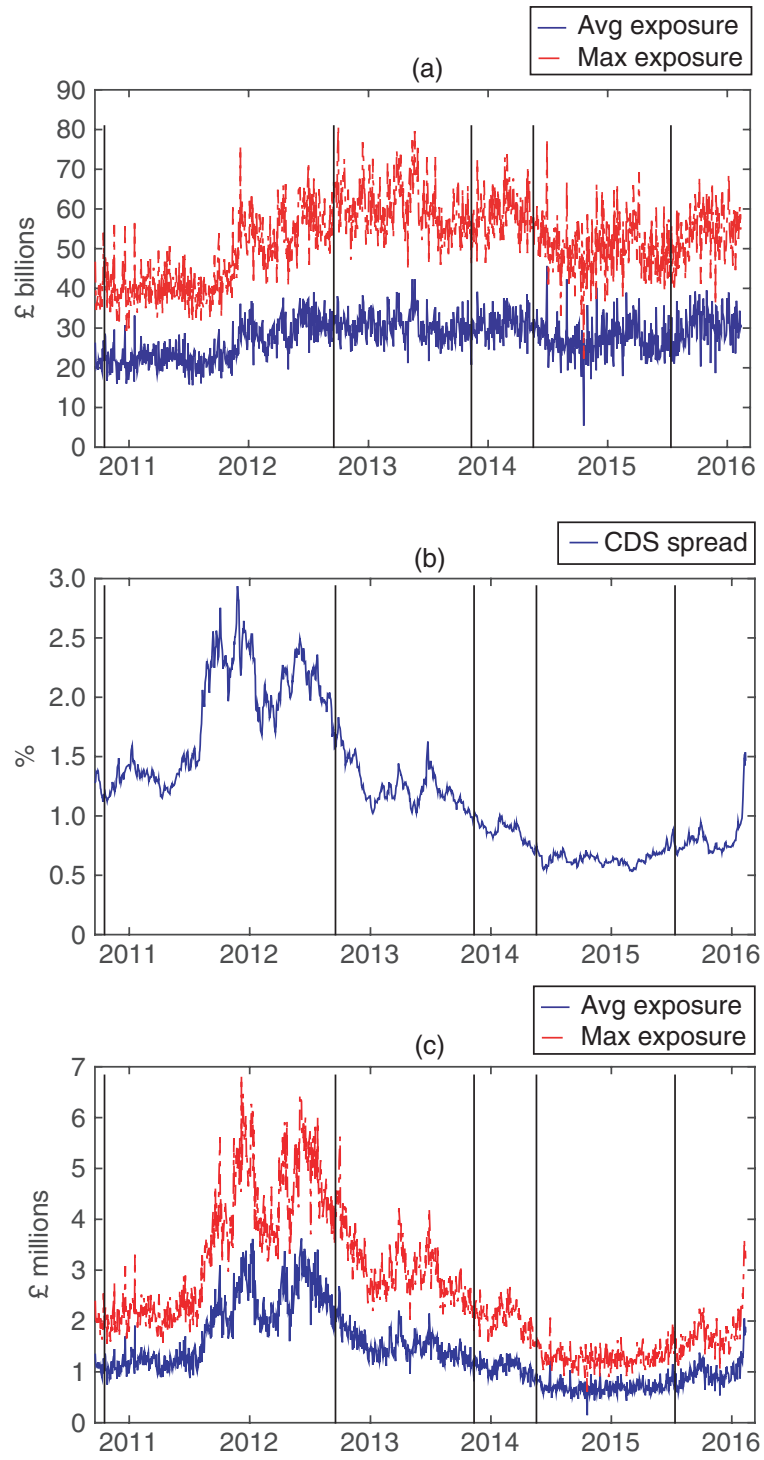

(a) Aggregate daily intraday credit exposure (Avg_Exposure ${ }_{s}$ and Max_Exposure S $_{\text {) }}$ arising between all first- and second-tier institutions. Avg_Exposure ${ }_{s}$ and Max_Exposure ${ }_{s}$ are defined in (4.10). (b) Average daily CDS spread across CHAPS banks (\%, annualized). (c) Aggregate expected daily cost of credit risk (in £ millions) as per (4.11), as calculated using Avg_Exposure (blue line) and Max_Exposure (red dotted line). The vertical lines denote the de-tiering events. The time period is from September 20, 2010 to February 12, 2016. 


\subsection{Liquidity cost}

When a first-tier bank assumes a net debit position (ie, pays more than it receives), it deploys its own liquidity to make up the difference. To make payments in those instances, the bank may either use its own reserves or borrow intraday from the Bank of England on a collateralized basis. In either case, deploying one's own liquidity has an opportunity cost, because reserves and collateral could potentially be used elsewhere and be remunerated. Therefore, the cost of own liquidity usage is the opportunity cost associated with reserves and collateral held by CHAPS banks for the purpose of meeting their payment obligations. As we explained earlier, de-tiering should in theory lead to higher liquidity costs both because there is less opportunity for first-tier banks to recycle clients' incoming payments, in order to make their own payments (pooling), and because there is less scope for settling payment obligations between clients of the same first-tier bank on the latter's books rather than through CHAPS (internalization). In this section, we assess the impact of the de-tiering events in our sample on the cost of liquidity usage among CHAPS banks.

Based on the above discussion, the liquidity cost of first-tier bank $i$ on day $s$ is

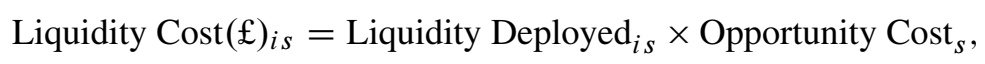

where "Liquidity Deployed" is a function of the bank's net debit positions attained during the day. The aggregate liquidity cost across all CHAPS banks is then

$$
\text { Aggr. Liquidity } \operatorname{Cost}(\mathfrak{E})_{s}=\sum_{i} \text { Liquidity } \operatorname{Cost}(\mathfrak{E})_{i s},
$$

where the sum is over all first-tier banks active on day $s$.

The resources that banks hold to meet their daily liquidity needs are used whenever the cumulative amount of outgoing payments exceeds that of incoming payments. Given that these resources are pledged for the entire day, the amount of liquidity deployed by a CHAPS bank equals the maximum net debit position attained during the day, regardless of whether this liquidity is deployed for only a brief period of time. Thus, if $P_{i s t}^{\text {OUT/IN }}$ is the cumulative amount paid/received by first-tier bank $i$ on day $s$ and up to time $t$, the liquidity deployed by this bank is then

$$
\text { Liquidity Deployed }_{i s}=\max _{t}\left\{\max \left\{P_{i s t}^{\mathrm{OUT}}-P_{i s t}^{\mathrm{IN}}, 0\right\}\right\} \text {. }
$$

It is worth noting here that the deployed liquidity is calculated using all first-tier bank payments, ie, the payments made/received on its own behalf as well as those made/ received on behalf of its clients. ${ }^{16}$

\footnotetext{
${ }^{16}$ Second-tier banks do not use any of their own liquidity to make payments, since they have no access to CHAPS. All of the liquidity required for their payments is provided for by their firsttier correspondents. Further, first-tier correspondents can choose when, during the day, to make a payment on behalf of a second-tier bank, unless that payment is time sensitive. First-tier banks choose the timing of these payments to minimize liquidity usage.
} 
FIGURE 4 Frequency distribution of daily deployed liquidity (in $£$ billions) before and after the de-tiering events by each of those first-tier banks with a client who joins the first tier.

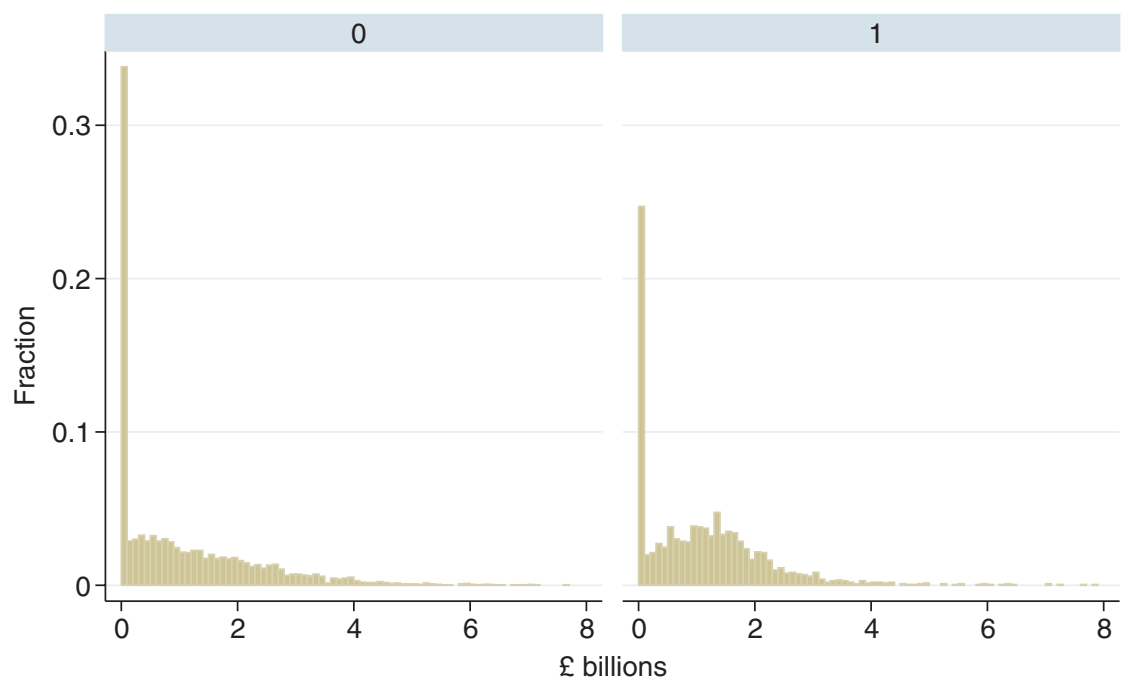

To ease visualization, deployed liquidity has been truncated at $£ 8$ billion in this chart. There are only nine instances in our sample of deployed liquidity that is greater than $£ 8$ billion, representing less than $0.16 \%$ of the frequency distribution. The maximum deployed liquidity is $£ 16.85$ billion. The sample period is September 20, 2010 to February 12, 2016.

To assess the impact of de-tiering on the cost of liquidity, we first look at the deployed liquidity of those first-tier banks that had a client joining the first tier. Figure 4 shows the frequency distribution of daily deployed liquidity across each of the affected first-tier banks before and after the de-tiering events. Figure 4 shows that after the de-tiering events, affected first-tier banks seem to be using more of their own liquidity, which is consistent with what one would expect. For example, while - prior to the de-tiering events - affected first-tier banks do not deploy any of their own liquidity about $35 \%$ of the time, this number drops to $25 \%$ after the de-tiering events. However, the overall amounts of deployed liquidity are generally small. Aside from the fact that on about $30 \%$ of all days (before and after the de-tiering events), affected banks do not deploy any liquidity at all, even when they do deploy their own liquidity, the amount used rarely exceeds $£ 5$ billion per bank. These amounts are small compared with the average daily payments of about $£ 43$ billion that each of these banks makes.

To more formally assess the impact of de-tiering on liquidity usage and costs, we next estimate a panel fixed-effects model of deployed liquidity across these affected 
first-tier banks:

$$
\text { LIQDEPL }_{i s}=a+b \text { Event }_{i s}+c \text { Pmts }_{i s}+d \text { SONIA }_{s}+u_{i}+e_{i s} .
$$

As before, $i$ denotes banks, $s$ denotes days, LIQDEPL is the amount of liquidity deployed as defined in (4.14), "Event" is the bank-specific de-tiering event dummy, "Pmts" is the amount of payments made by each bank and SONIA is the sterling overnight index average rate. ${ }^{17}$ The last two variables are included as controls, as one would expect the amount of liquidity used to be higher with payments made and lower with the interbank borrowing cost.

It is also worth noting that any effects on the liquidity usage of those first-tier banks with joining clients would primarily be because of the absence of pooling, as these banks would not be able to use the incoming payments of their joining clients after each of the de-tiering events. Internalization should not affect these first-tier banks, as the onus is primarily on the joining second-tier clients to supply the liquidity required for their own payments.

Table 5 shows the results of this estimation. As one can see from the estimated coefficients of the "Event" dummy, while de-tiering is associated with increased amounts of deployed liquidity by affected first-tier banks, the effect is not statistically significant. This could be because the high degree of tiering gives first-tier banks access to alternative client liquidity even after one of their bigger clients has joined the first tier. Such an explanation would be consistent with the large number of days with zero liquidity usage that we observe. Alternatively, it could be because the banks joining the first tier have similar payment patterns with the other second-tier banks, so there is limited pooling of offsetting flows in the first place. ${ }^{18}$ The other control variables are also statistically insignificant.

We also look at the impact of the de-tiering events on aggregate liquidity usage, which is the sum of the liquidity usage of all first-tier banks. We do this because we want to capture any additional effects of de-tiering on deployed liquidity arising from reduced internalization. Figure 5 shows the amounts of aggregate liquidity deployed by those banks that are consistently on the first tier during our sample time (ie, excluding the joining banks) as well as of all banks that are on the first tier at any point in time. Legacy first-tier banks deploy less of their own liquidity over time, but this appears to be partly offset by the liquidity that new entrants deploy. As a result, and despite daily fluctuations between $£ 10$ billion and $£ 20$ billion, deployed liquidity across all banks remains relatively stable during our sample time. The de-tiering

\footnotetext{
${ }^{17}$ In one case, a single first-tier bank was affected by two de-tiering events. In that case, this dummy takes the value 1 only after the second de-tiering event. It ignores the first de-tiering because it happened very early in our sample period.

${ }^{18}$ We thank Peter Zimmerman for this observation.
} 
TABLE 5 CHAPS bank own liquidity usage around de-tiering events.

\begin{tabular}{rccccc}
\hline & \multicolumn{4}{c}{ Liquidity deployed (LIQDEPL) } \\
\cline { 3 - 5 } Event & $\mathbf{( 1 )}$ & $\mathbf{( 2 )}$ & $\mathbf{( 3 )}$ & $\mathbf{( 4 )}$ \\
& 0.0325 & 0.0830 & 0.1650 & 0.2594 \\
SONIA & $(0.12)$ & $(0.45)$ & $(0.46)$ & $(0.94)$ \\
& & 1.2929 & & 2.1797 \\
Pmts & & $(0.55)$ & & $(0.79)$ \\
& & & 0.0267 & 0.0286 \\
Const & $1.0789^{* \star *}$ & 0.4620 & -0.1277 & -1.2526 \\
& $(11.04)$ & $(0.45)$ & $(-0.19)$ & $(-0.83)$ \\
$R^{2}$ & 0.000 & 0.002 & 0.023 & 0.027 \\
$N$ & 5460 & 5460 & 5460 & 5460 \\
\hline
\end{tabular}

events do not appear to be associated with sizable changes in aggregate deployed liquidity. ${ }^{19}$

To quantify the cost of liquidity usage by CHAPS banks, we use the overnight index average (SONIA) rate as a proxy for the opportunity cost of own liquidity usage. The rationale is that the liquidity used to make payments could be alternatively loaned out in the interbank market. Figure 6 plots the SONIA rate over our sample period and the daily aggregate cost of deploying liquidity, as calculated by (4.13). The figure shows that this cost fluctuates between $£ 15000$ and $£ 40000$ daily for all CHAPS banks.

Overall, de-tiering does not seem to have had a sizable effect on the amounts of deployed liquidity of first-tier banks, while the associated cost of deploying this liquidity appears, in any case, to be relatively small.

\subsection{Operational risk}

Finally, we attempt to assess and quantify the amount of operational risk associated with the tiered structure of CHAPS. The Basel Committee on Banking Supervision (2011) defines operational risk as the risk of losses resulting from inadequate or failed internal processes, from human error or from external events. This definition includes legal risk but excludes strategic and reputational risk. In our analysis, we are concerned

\footnotetext{
${ }^{19} \mathrm{We}$ also formally test this in time series regressions. The regression results confirm the absence of any significant effects of de-tiering on aggregate liquidity usage. The regression results are available upon request.
} 
FIGURE 5 Aggregate liquidity deployed (in £ billions) of legacy first-tier banks, and of all banks.

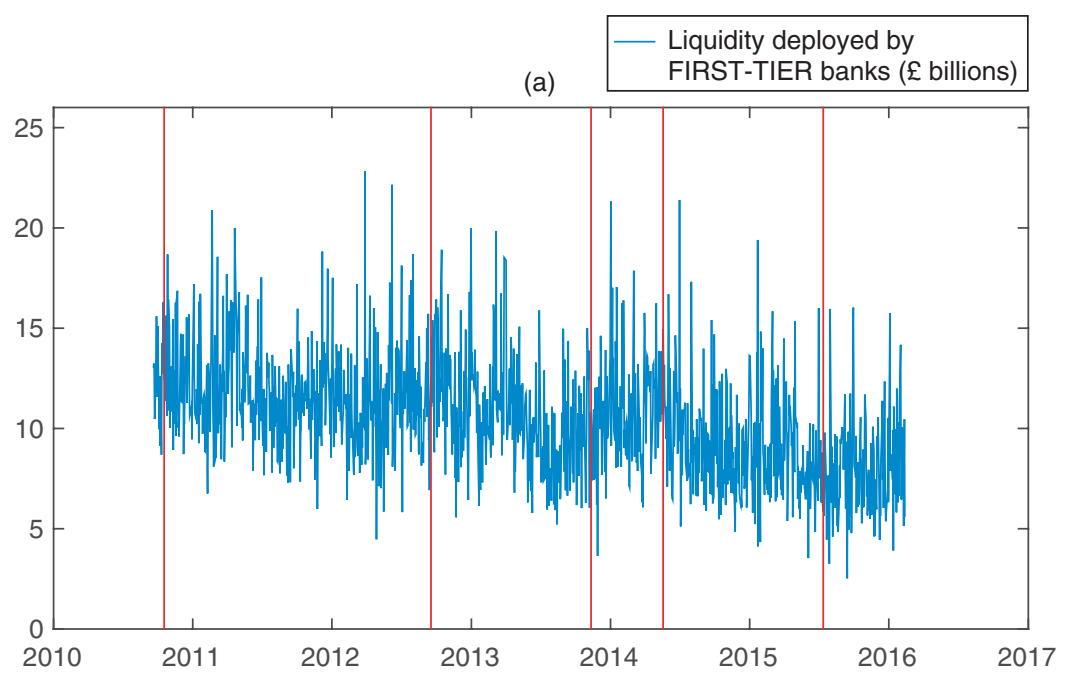

(b) - Total liquidity deployed (£ billions)

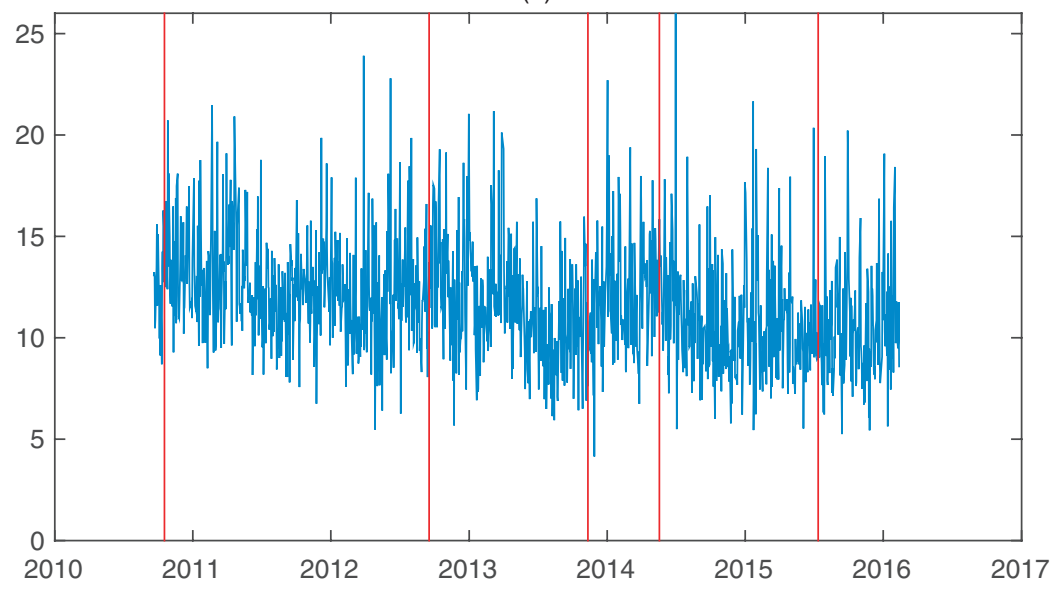

(a) Legacy first-tier banks. (b) All first-tier banks. Aggregate liquidity deployed is the sum of individual CHAPS bank deployed liquidity as defined in (4.14). The vertical lines denote de-tiering events. The time period is from September 20, 2010 to February 12, 2016.

about the risk of individual first-tier banks' operational outages. ${ }^{20}$ When a first-tier

${ }^{20} \mathrm{We}$ do not consider outages of the entire payment system where all first-tier institutions are affected. If anything, a less tiered system is more vulnerable to a system-wide outage, as there is less scope for payments across second-tier banks to be internalized. 
FIGURE 6 SONIA (in \%, annualized) and daily aggregate liquidity cost (in $£$ thousands).
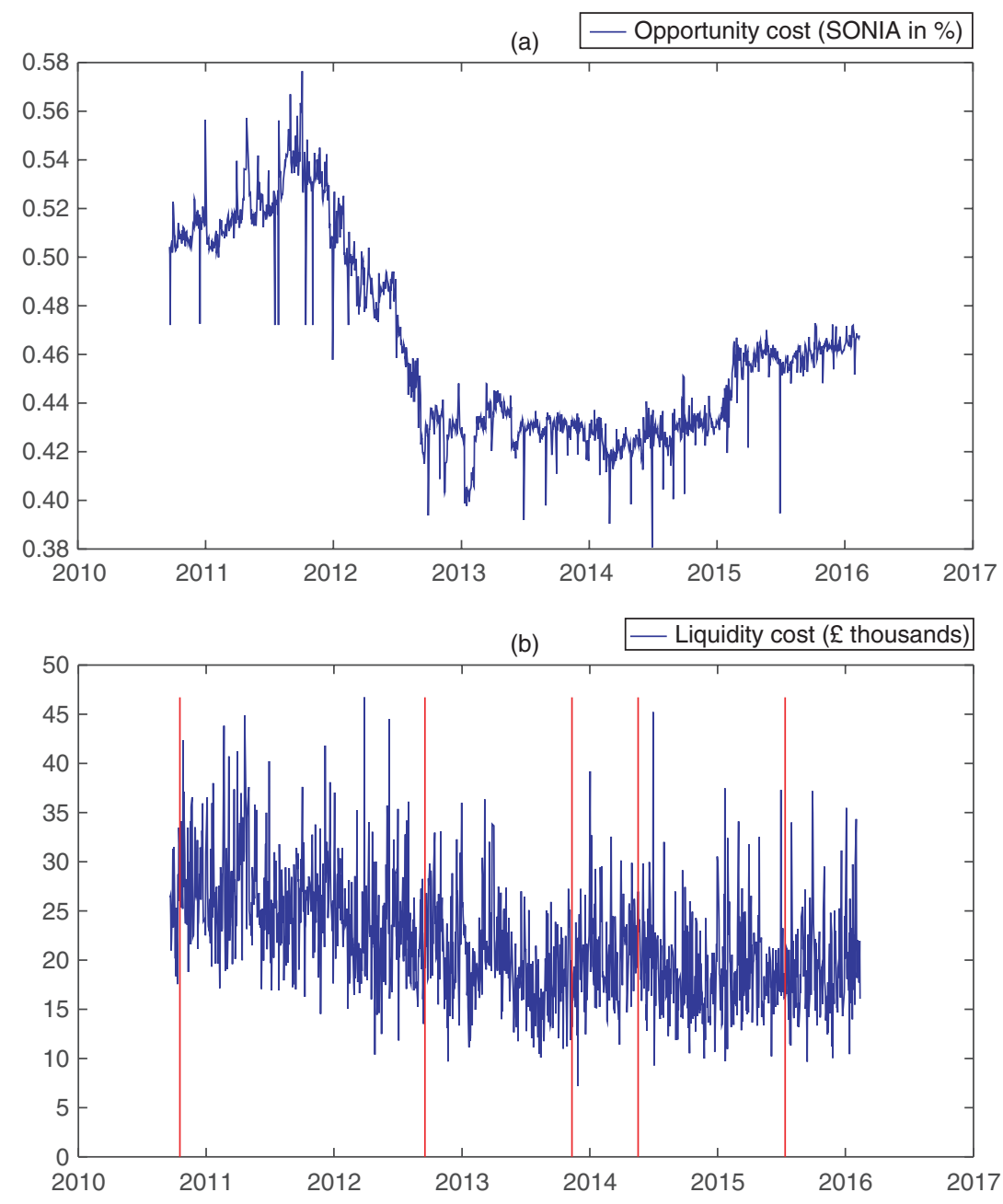

(a) SONIA (\%). (b) Actual liquidity cost. Aggregate liquidity cost is defined in (4.13). The vertical lines denote de-tiering events. The time period is from September 20, 2010 to February 12, 2016.

bank experiences an operational outage that prevents it from sending payments to or receiving payments from other banks, the second-tier clients of the stricken bank would also not be able to make payments to or receive payments from any other banks that are not clients of the same stricken bank. Thus, as tiering decreases, an operational outage at the first tier would affect fewer banks in the second tier, but the probability of observing an outage on any particular day will increase. 
We measure the cost of operational risk as the expected opportunity cost of the delayed payments that accrues to the banks receiving these payments. In focusing on the opportunity cost of delayed payments, we make the following assumptions.

(a) During an outage, a stricken bank may receive but not send payments (potentially becoming what is known as a liquidity sink). This is consistent with the CHAPS outage record, where about $90 \%$ of observed outages involve banks that cannot make payments but can receive them.

(b) No defaults can occur as a result of payment delays associated with an outage. In other words, if a bank fails to make a payment because of an outage, then we assume that this bank will not be forced into default by the bank expecting to receive that payment. We assume that, in those instances, any binding contractual obligations can be renegotiated. This assumption is based on the observation that no bank in the United Kingdom has so far been driven into default because of an operational incident.

(c) There is neither a reputational cost nor any gain whatsoever to the sender of a delayed payment. While reputational costs may exist, we abstract away from them in our analysis, as they are hard to quantify.

(d) Payments on behalf of second-tier banks are uniformly distributed during the day so that only the duration (and not the time) of the outage matters. This assumption is justified by the use of throughput rules in CHAPS, where banks must, on average over the course of each month, make at least $50 \%$ of their outgoing payments by noon and $75 \%$ of their payments by $14: 30$.

We note that the degree of tiering is unrelated to the cost incurred by the counterparty of a first-tier bank whose own payments are delayed because of an operational outage. For this reason, we only consider delays in payments by first-tier banks that are made on behalf of their second-tier clients.

\subsubsection{The expected cost of operational risk}

As mentioned above, to calculate the expected cost of operational risk, we only consider delayed payments by first-tier banks that are made on behalf of their second-tier clients. Let $P_{s T}^{\mathrm{OUT}}(i, j)$ be the cumulative amount of payments made by bank $i$ on behalf of bank $j$ on day $s$. In addition, let $\tilde{X}_{i}$ be the random number of outages that affect bank $i$ on each day, let $\tilde{D}$ be the random duration of each outage expressed in fractions of a business day and let $r_{s}$ be the daily cost of overnight unsecured borrowing as captured by the SONIA rate. Then, an estimate of the daily expected 
TABLE 6 Summary statistics of daily expected costs of operational risk (in £ thousands) as per (4.17).

\begin{tabular}{lrrrrrrr}
\hline \multicolumn{1}{c}{ Statistics } & $\mathbf{2 0 1 0}$ & $\mathbf{2 0 1 1}$ & $\mathbf{2 0 1 2}$ & $\mathbf{2 0 1 3}$ & $\mathbf{2 0 1 4}$ & $\mathbf{2 0 1 5}$ & $\mathbf{2 0 1 6}$ \\
\hline Mean & 7.7 & 8.4 & 8.4 & 5.9 & 3.2 & 9.7 & 14.7 \\
Standard deviation & 1.0 & 1.0 & 0.9 & 0.6 & 0.3 & 1.1 & 1.5 \\
Minimum & 4.6 & 5.9 & 5.6 & 4.2 & 1.6 & 6.4 & 10.4 \\
Maximum & 10.3 & 12.6 & 11.3 & 8.5 & 4.2 & 13.2 & 18.1 \\
\hline
\end{tabular}

opportunity cost that accrues to the recipients of payments that are being delayed because of an outage at bank $i$ on day $s$ is

$$
\mathbb{E}[\text { Operational Risk Cost }]_{i s}=\left[\sum_{j} P_{s T}^{\mathrm{OUT}}(i, j)\right] \times\left(\bar{X}_{i} \times \bar{D}\right) \times\left(r_{s} \times \bar{D}\right),
$$

where $\bar{X}_{i}$ and $\bar{D}$ are the means of $\tilde{X}_{i}$ and $\tilde{D}$, respectively. ${ }^{21}$ This expression effectively calculates the fraction of total daily payments that is subject to delays and multiplies it by the opportunity cost that corresponds to the expected time delay. The daily aggregate expected cost of operational risk across all first-tier banks is the sum of the individual bank expected costs:

$$
\mathbb{E}[\text { Operational Risk Cost }]_{s}=\sum_{i} \mathbb{E}[\text { Operational Risk Cost }]_{i s} .
$$

We calculate this expression using data on daily payments and on the number and duration of operational outages among CHAPS banks, which is collected and maintained by the Bank of England. The average number of outages and their durations are estimated every year to account for any changes in these means as a result of the de-tiering events during our sample time.

Table 6 shows summary statistics of the daily values of the expected cost of operational outage, as per (4.17), for each of the years in our sample. On average, the expected aggregate opportunity cost of delayed payments fluctuates between $£ 3000$ and $£ 15000$ daily, an economically small amount. Further, this cost is not declining (or increasing) over time, so it appears to be unrelated to the degree of tiering in CHAPS. Given the small size of this effect, we forgo a more formal statistical test of changes in the cost of operational risk after each of the de-tiering events.

In conclusion, given the assumptions stated at the beginning of this section, it appears that the overall economic effect of payment delays associated with operational risk is small. Further, de-tiering does not seem to have any impact on this cost.

${ }^{21}$ This expression implicitly assumes that the payments are uniformly distributed throughout the day. 


\section{CONCLUSIONS}

In this paper, we use data from CHAPS, the UK LVPS, to study the impact of correspondent banking (known as tiering) on credit, liquidity and operational risk as well as the economic significance of these risks. To this end, we exploit five de-tiering events that occurred in CHAPS over the past several years. As such, ours is the first study to capture actual (rather than simulated) effects associated with changes in a tiered payment structure.

Our results suggest that the CHAPS de-tiering events in our sample bring about a reduction in the intraday exposures between first- and second-tier banks to the order of $£ 0.3$ billion to $£ 1.5$ billion per bank. While these numbers are not trivial, there are several reasons why they are not larger. First, when moving to the first tier, most banks continue, to some degree, to obtain (and supply) intraday credit from (to) their former corresponding banks. Second, because of our assumption that at most one second-tier client may default on a given day, we calculate the intraday exposures of first-tier banks as the maximum of their exposures across their second-tier clients. This assumption implies that even after a client bank joins the first tier, its correspondent will still be exposed to what used to be the second-largest client. Thus, in instances where the client banks are of similar size, the correspondent's exposure to its single largest client may not change substantially.

The cost of credit risk is estimated by the cost of insuring against the losses arising from any intraday exposures toward a defaulting correspondent or second-tier bank. Given the reduction in exposures, the cost of insuring against losses arising from these exposures also drops. For average intraday exposures, we estimate this cost reduction to be between $£ 4$ million and $£ 19$ million per bank, per year.

We also find that the effect of de-tiering on the amount and cost of bank-deployed liquidity is small, where the cost of liquidity is approximated by the opportunity cost of holding liquid assets. The effect is small firstly because the actual amounts of deployed liquidity in CHAPS are modest (presumably due to payment recycling) and do not change much after the de-tiering events, and secondly because the opportunity cost of holding liquid assets is low over our sample period.

Finally, we find that the opportunity cost incurred by the recipients of payments that are delayed, because of operational incidents, is also small. This suggests that the operational risk accruing because of tiering is economically small. We should mention, however, that in assessing the impact of a tiered structure on operational risk, we assume that such unintentional payment delays do not result in contractual obligations being breached or payers being forced into default by their counterparties.

Although it is not clear if the above effects would be smaller or larger if CHAPS were to be further de-tiered, our findings do suggest that the tiered structure of CHAPS 
is primarily associated with intraday credit risk; otherwise, it does not appear to be associated with substantial liquidity or operational risks.

\section{DECLARATION OF INTEREST}

The views expressed in this paper are those of the authors, and not necessarily those of the Bank of England or its committees.

\section{ACKNOWLEDGEMENTS}

We thank Ronald Heijmans, the SWP referee, for his excellent feedback. We are also grateful to Paul Bedford, James Chapman, Jorge Cruz Lopez, Nick Davey, Andrew Dent, Gary Harper, Andrew Hauser, Ana Lasaosa, Mark Manning, Jan Paulick (discussant), Patrick Papsdorf (discussant), Gary Robinson, Rhiannon Sowerbutts, Graham Young, Peter Zimmerman, seminar participants at the Bank of England, participants of the 2016 conference on the Economics of Payments hosted by the Bundesbank in Eltville, participants of the 2016 conference on payments hosted by the Bank of Canada and Payments Canada in Ottawa, and the anonymous referees of the Journal of Financial Market Infrastructures for helpful comments. We also thank David Norcross for his help in retrieving the data. Any errors are ours.

\section{REFERENCES}

Abbink, K., Bosman, R., Heijmans, R., and van Winden, F. (2017). Disruptions in large value payment systems: an experimental approach. International Journal of Central Banking, forthcoming.

Adams, M., Galbiati, M., and Giansante, S. (2010). Liquidity costs and tiering in large-value payment systems. Staff Working Paper 399, Bank of England.

Arculus, R., Hancock, J., and Moran, G. (2012). The impact of payment system design on tiering incentives. Research Discussion Paper 2012-06, Reserve Bank of Australia.

Bank of England (2004a). Strengthening financial infrastructure. Financial Stability Review 17, December, Bank of England, pp. 74-85.

Bank of England (2004b). Payment systems oversight report 2004, pp. 23-24.

Basel Committee on Banking Supervision (2011). Principles for the sound management of operational risk. Report, June, Bank for International Settlements.

Bech, M., and Garratt, R. (2003). The intraday liquidity management game. Journal of Economic Theory 109(2), 198-219 (https://doi.org/10.1016/S0022-0531(03)00016-4).

Bech, M., and Garratt, R. (2012). Illiquidity in the interbank payment system following widescale disruptions. Journal of Money, Credit and Banking 44(5), 903-929 (https://doi.org/ 10.1111/j.1538-4616.2012.00515.x).

Becher, C., Millard, S., and Soramaki, K. (2008). The network topology of CHAPS sterling. Staff Working Paper 355, Bank of England. 
Bedford, P., Millard, S., and Yang, J. (2004). Assessing operational risk in CHAPS sterling: a simulation approach. Financial Stability Review 16, June, Bank of England, pp. 135-143.

Benos, E., and Harper, G. (2016). Recycling is good for the liquidity environment: why ending QE shouldn't stop banks from being able to make CHAPS payments. Bank Underground, May 18.

Benos, E., Garratt, R., and Zimmerman, P. (2012). Bank behavior and risks in CHAPS following the collapse of Lehman Brothers. Staff Working Paper 451, Bank of England.

Benos, E., Garratt, R., and Zimmerman, P. (2014). The role of counterparty risk in CHAPS following the collapse of Lehman Brothers. International Journal of Central Banking 10(4), 143-171. URL: www.ijcb.org/journal/ijcb14q4a5.pdf.

Berge, O., and Christophersen, C. (2012). Operational problems in banks - effects on the settlement of payments in Norges Bank. Norges Bank Economic Bulletin 83, 36-47.

Chapman, J., Chiu, J., and Molico, M. (2013). A model of tiered settlement networks. Journal of Money, Credit and Banking 45, 327-347 (https://doi.org/10.1111/jmcb.12004).

Clarke, A., and Hancock, J. (2013). Payment system design and participant operational disruptions. The Journal of Financial Market Infrastructures 2(2), 53-76 (https://doi.org/ 10.21314/JFMI.2013.023).

Committee on Payment and Settlement Systems-Technical Committee of the International Organization of Securities Commissions (2012). Principles for financial market infrastructures. Report, Bank for International Settlements. URL: http://bit.ly/1mcqA8x.

Committee on Payments and Market Infrastructures (2016). Statistics on payment, clearing and settlement systems in the CPMI countries: figures for 2015. Report, December, Bank for International Settlements. URL: www.bis.org/cpmi/publ/d155.htm.

Deloitte (2015). Independent review of RTGS outage on 20 October 2014. Report, March 23, Deloitte.

Denbee, E., Garratt, R., and Zimmerman, P. (2015). Variations in liquidity provision in real-time payment systems. Staff Working Paper 513, Bank of England.

Finan, K., Lasaosa, A., and Sunderland, J. (2013). Tiering in CHAPS. Quarterly Bulletin Q3, Bank of England, pp. 371-378.

Financial Conduct Authority and Payments Systems Regulator (2014). Access to UK payment systems. Background Paper: Access Event, June 5, FCA-PSR. URL: http://bit.ly/ 2CipsZU.

Frachot, A., Georges, P., and Roncalli, T. (2001). Loss distribution approach for operational risk. Working Paper, Groupe de Recherche Opérationnelle, Crédit Lyonnais.

Harrison, S., Lasaosa, A., and Tudela, M. (2005). Tiering in UK payment systems. Financial Stability Review, June, Bank of England, pp. 63-72.

International Monetary Fund (2016). United Kingdom financial sector assessment program. Country Report 16/156, June, IMF. URL: http://bit.ly/2Ambg0F.

Jackson, J., and Manning, M. (2007). Central bank intraday collateral policy and implications for tiering in RTGS payment systems. Working Paper 129, DNB.

Jurgilas, M., and Zikes, F. (2014). Implicit intraday interest rate in the UK unsecured overnight money market. Journal of Financial Intermediation 23(2), 232-254 (https:// doi.org/10.1016/j.jfi.2013.11.002).

Kahn, C. M., and Roberds, W. (1998). Payment system settlement and bank incentives. Review of Financial Studies 11(4), 845-870 (https://doi.org/10.1093/rfs/11.4.845). 
Kahn, C. M., and Roberds, W. (2009). Payments settlement: tiering in private and public systems. Journal of Money, Credit and Banking 41(5), 855-884 (https://doi.org/10.1111/ j.1538-4616.2009.00236.x).

Lai, A., Chande, N., and O'Connor, S. (2006). Credit in a tiered payment system. Working Paper 2006-36, Bank of Canada.

Lasaosa, A., and Tudela, M. (2008). Risk and efficiency gains in a tiered structure in largevalue payments: a simulation approach. Staff Working Paper 337, Bank of England.

Manning, M., Nier, E., and Schanz, J. (2009). The Economics of Large-Value Payments and Settlement: Theory and Policy Issues for Central Banks. Oxford University Press.

Mas-Colell, A., Whinston, M., and Green, J. (1995). Microeconomic Theory. Oxford University Press.

Merrouche, O., and Schanz, J. (2009). Banks' intraday liquidity management during operational outages: theory and evidence from the UK payment system. Staff Working Paper 370, Bank of England.

Norman, B., Shaw, R., and Speight, G. (2011). The history of interbank settlement arrangements: exploring central banks' role in the payment system. Staff Working Paper 412, Bank of England.

Rochet, J.-C., and Tirole, J. (1996). Controlling risk in payment systems. Journal of Money, Credit and Banking 28(4), 832-862 (https://doi.org/10.2307/2077924).

Salmon, C. (2011). The case for more CHAPS settlement banks. Speech, Yorkshire and Humberside Network of the ifs School of Finance, Leeds. 